\title{
Pengembangan Teknologi Imaging untuk Pemantauan Parameter Opasitas Asap Hitam pada Cerobong Industri
}

\author{
Ahmad Maulana Syafii ${ }^{1}$, Muhammad Rifki Muheimin ${ }^{2}$, Esa Prakasa ${ }^{3}$ \\ ${ }^{1}$ Matematika, Matematika dan Teknologi Informasi, Institut Teknologi Kalimantan, Balikpapan. \\ Email:02131004@itk.ac.id \\ ${ }^{2}$ Matematika, Matematika dan Teknologi Informasi, Institut Teknologi Kalimantan, Balikpapan. \\ Email:02131001@itk.ac.id \\ ${ }^{3}$ P2I, LIPI, Bandung. Email:esa.prakasa@mail.com
}

\begin{abstract}
The Increased industrial subsector in Indonesia each year have some negative impact on health in Indonesia. Exhaust emissions of industrial activities is one of the sources of air pollution that occurs continuously. Exhaust gas quality monitoring needs to be done regularly to control the level of air pollution as required under KepMenLH 13/1995. During the determination of the opacity of the black smoke chimney industry performed manually using Ringlemann. Results opasitasbergantung on the observer on the ground so that the level of accuracy obtained is still less opacity akurat. Paper is about the development of imaging technology for monitoring parameters of black smoke in the exhaust stack opacity industri.Metode measurement used in this monitoring is a method Ringlemann. Segmentation algorithm used in this research is using thresholding. The result of the automatic segmentation using thresholding sample data has a high degree of accuracy, but still dependent on weather conditions. If you do smoke segmentation when the sky is clear, the level of accuracy of the segmentation is very high, but it is different when overcast or cloudy weather conditions. Results from this study is the obtainment function to be able to determine the level of black smoke opacity parameter. Searches made through a logarithmic function. Determination of the proper function is determined by looking at the highest value of $\mathrm{R}^{2}$. Different sky conditions lead to different functions, so the algorithm functions to determine the parameters of black smoke opacity made in some circumstances under the conditions of the sky.
\end{abstract}

Keywords: Imaging, Opacity, Ringgelmann, Thresholding

\begin{abstract}
Abstrak
Peningkatan subsektor industri di Indonesia setiap tahunnya memiliki beberapa dampak negatif bagi kesehatan di Indonesia. Emisi gas buang kegiatan industri adalah salah satu sumber pencemaran udara yang terjadi secara terus-menerus. Pemantauan kualitas gas buang perlu dilakukan secara berkala untuk mengendalikan tingkat pencemaran udara sebagaimana diwajibkan dalam KepMenLH No.13/1995. Selama ini penentuan opasitas asap hitam cerobong industri dilakukan secara manual menggunakan metode Ringlemann. Hasil opasitas bergantung pada pengamat di lapangan sehingga tingkat keakuratan opasitas yang didapat masih kurang akurat.Paper ini membahas tentang pengembangan teknologi imaging untuk pemantauan parameter opasitas asap hitam pada cerobong industri.Metode pengukuran yang digunakan dalam pemantauan ini adalah Metode Ringlemann. Algoritma segmentasi yang digunakan pada penelitian ini ialah menggunakan thresholding. Hasil segmentasi otomatis pada data sampel menggunakan thresholding memiliki tingkat akurasi yang tinggi namun masih bergantung pada kondisi cuaca. Jika dilakukan segmentasi asap saat langit cerah maka tingkat akurasi hasil segmentasi sangat tinggi, namun berbeda saat kondisi cuaca mendung atau berawan. Hasil dari penelitian ini ialah didapatkannya fungsi untuk bisa menentukan tingkat parameter opasitas asap hitam. Pencarian fungsi dilakukan melalui pendekatan logaritmik. Penentuan fungsi yang tepat ditentukan dengan melihat nilai $R^{2}$ terbesar. Kondisi langit yang berbeda menyebabkan fungsi yang berbeda, sehingga algoritma fungsi dalam menentukan parameter opasitas asap hitam dibuat dalam beberapa kondisi sesuai kondisi langit.
\end{abstract}

Kata Kunci: Imaging, Opacity, Ringgelmann, Thresholding

\section{Pendahuluan}

Perkembangan dan pertambahan penduduk Indonesia yang semakin pesat mengakibatkan munculnya program-program pembangunan di segala bidang kehidupan. Salah satu ciri pelaksanaan dari program 
pembangunan tersebut yaitu berkembangnya sektor perindustrian. Menurut Badan Pusat Statistik Indonesia jumlah perusahaan industri di Indonesia hingga akhir tahun 2013 sebanyak 23.941 industri yang terdiri dari beberapa subsektor. Perkembangan sektor industri dapat memberikan dampak positif terhadap meningkatnya taraf hidup manusia. Namun sektor industri juga memberikan dampak negatif terhadap pencemaran udara. Salah satu pencemar udara yang tidak luput dari aktivitas perindustrian yaitu asap.

Tingkat kepekatan asap disebut opasitas. Tingkat opasitas yang baik harus memenuhi standar baku mutu yang tercantum dalam Keputusan Menteri Lingkungan Hidup No.13 Tahun 1995 tentang Baku Mutu Emisi Sumber Tidak Bergerak. Oleh karena itu pemantauan kualitas gas buang industri perlu dilakukan secara berkala untuk mengendalikan tingkat pencemaran udara.

Penentuan opasitas di Indonesia selama ini masih dilakukan secara manual menggunakan kasat mata. Metode yang digunakan para pengamat untuk menentukan opasitas ialah metode Ringgelmann. Adapun hasil yang didapatkan dalam penentuan opasitas secara manual masih memiliki kekurangan yaitu kurang objektif dan kurang akurat. Berdasarkan latar belakang tersebut maka diusulkan penelitian Pengembangan Teknologi Imaging untuk Pemantauan Parameter Opasitas Asap Hitam pada Cerobong Industri. Dalam penelitian ini akan dibahas mengenai algoritma untuk mendapatkan fungsi persamaan opasitas sehingga penentuan opasitas menjadi lebih akurat dibanding pemantauan secara manual.

\section{Metode}

Metode yang dilakukan pada penelitian ini ialah pengolahan citra dengan cara thresholding (nilai ambang batas). Thresholding adalah salah satu teknik pengolahan citra yang dilakukan dengan cara memberikan nilai 1 dan 0 (putih dan hitam). Segmentasi gambar bertujuan untuk mempermudah perhitungan nilai thresholding. Hasil segmentasi akan dicocokan dengan skala ringgelman dengan melihat liat opasitas pada gambar asap dan langit.

\subsection{Pengolahan Citra Digital}

Pengolahan citra digital (Digital Image Processing) adalah sebuah ilmu yang mempelajari teknik-teknik dalam mengolah citra agar kualitas citra yang dihasilkan menjadi lebih baik dari sebelumnya. Secara harafiah, citra (image) adalah gambar pada bidang dwimatra (dua dimensi). Citra yang dimaksud disini adalah gambar diam (foto) maupun gambar bergerak (yang berasal dari webcam). Jika ditinjau secara matematis, citra ialah suatu fungsi kontinu pada bidang dwimatra yang dengan intensitas cahaya di tiap pikselnya. Suatu citra harus bisa dipresentasikan secara numerik dengan nilai-nilai diskrit agar citra tersebut bisa diolah menggunakan komputer digital. Sebuah citra digital dapat diwakili oleh sebuah matriks dua dimensi $f(x, y)$ yang terdiri dari $\mathrm{M}$ kolom dan $\mathrm{N}$ baris, dimana perpotongan antara kolom dan baris disebut piksel (pixel $=$ picture element) atau elemen terkecil dari sebuah citra.

$$
f(x, y)=\left[\begin{array}{ccccc}
f(0,0) & f(0,1) & & \cdots & f(0,0) \\
f(1,0) & f(1,1) & \cdots & & f(0,0) \\
\vdots & \vdots & \vdots & \vdots \\
f(N-1,0) & f(N-1,1) & \cdots & f(N-1, M-1)
\end{array}\right]
$$

Suatu citra $f(x, y)$ dalam fungsi matematis dapat dituliskan sebagai berikut:

$$
\begin{gathered}
0 \leq x \leq M-1 \\
0 \leq y \leq N-1 \\
0 \leq f(x, y) \leq G-1
\end{gathered}
$$

dimana: $M=$ jumlah piksel baris (row) pada array citra

$N=$ jumlah piksel baris (column) pada array citra

$G=$ nilai skala keabuan (graylevel)

Besarnya nilai M,N, dan G pada umumnya perpangkatan dari dua.

$$
\mathrm{M}=2^{m} ; \mathrm{N}=2^{n} ; \mathrm{G}=2^{k}
$$


Dimana nilai $m, n$, dan $k$ adalah bilangan bulat positif. Interval $(o, G)$ disebut skala keabuan (grayscale). Besar $\mathrm{G}$ tergantung pada proses digitalisasinya. Biasanya keabuan 0 (nol) menyatakan intensitas hitam dan 1 (satu) menyatakan intensitas putih. Untuk citra 8 bit, nilai G sama dengan $2^{8}=256$ warna (derajat keabuan).

\subsection{Representasi Warna}

\subsubsection{Color image atau RGB (Red, Green, Blue)}

Colorimage atau RGB suatu model warna yang terdiri dari 3 warna yaitu merah (red), hijau (green) dan biru (blue). Jika ketiga warna ini ditambahkan maka akan menghasilkan warna yang bervariasi. Pada colorimage masing-masing warna memiliki range dari $0-255$, jadi dengan mengkombinasikan ketiga warna tersebut maka kita akan mendapatkan $256^{3}=16.777 .216$ variasi warna dalam setiap piksel. Colorimage ini terdiri dari matriks tiga dimensi yang tiap dimensinya memiliki nilai masing-masing yaitu red, green dan blue.

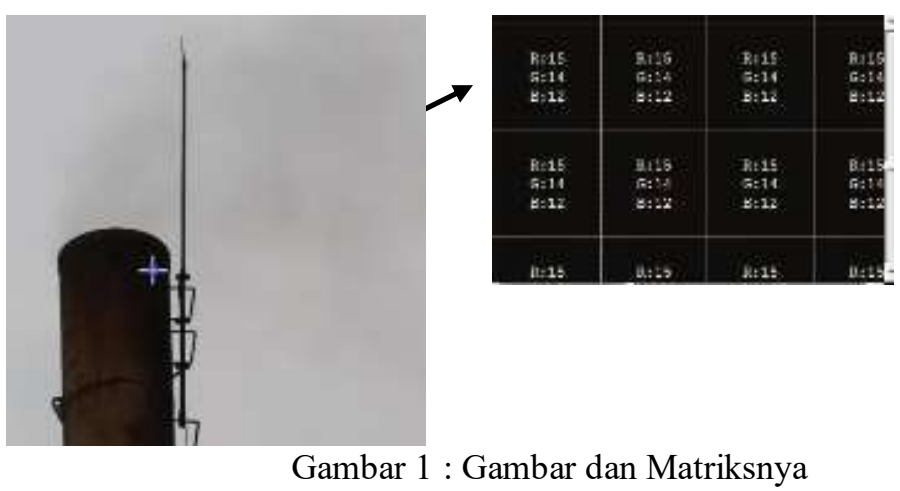

\subsubsection{Black and White}

Citra digital balck and white adalah gambar yang nilai setiap pikselnya adalah sampel tunggal yaitu hanya membawa informasi intensitas. Pada citra digital black and white setiap pikselnya mempunyai warna gradasi mulai dari putih sampai hitam. Pada umumnya setiap piksel tersebut dapat diwakili oleh 8-bit per piksel sehingga memungkinkan terdapat 256 variasi warna yang berbeda (yaitu, abu-abu) yang akan direkam. Citra digital black and white ini juga dikenal sebagai grayscale. Nilai grayscale sebenarnya merupakan hasil rata-rata dari 3 komponen warna yaitu red, green, dan blue. Persamaan matematisnya dapat dituliskan sebagai berikut :

$$
I_{B W}(x, y)=\frac{I_{r}(x, y)+I_{g}(x, y)+I_{b}(x, y)}{3}
$$

dengan

$I_{B W}(x, y)=$ Intensitas grayscale pada koordinat $x$ dan $y$.

$I_{r}(x, y)=$ Intensitas warna red pada koordinat $x$ dan $y$.

$I_{g}(x, y)=$ Intensitas warna green pada koordinat $x$ dan $y$.

$I_{b}(x, y)=$ Intensitas warna blue pada koordinat $x$ dan $y$.

\subsubsection{Binaryimage}

Setiap piksel pada citra ini hanya memiliki 2 variasi warna yaitu hitam atau putih. Karena hanya memiliki 2 warna untuk setiap piksel, maka hanya perlu 1 bit per piksel yaitu 0 (hitam) atau 1 (putih). Karena hanya membutuhkan 1 bit, maka pewarnaan ini cukup bagus digunakan untuk penyimpanan. Binaryimage sebenarnya proses lanjutan dari citra digital grayscale. Nilai grayscale yang berada dibawah nilai threshold maka akan dibawa ke warna hitam dan yang berada diatas threshold akan dibawa ke warna putih. Fungsi matematisnya dapat ditulis sebagai berikut :

$$
I_{b i n}(x, y)= \begin{cases}0, & I_{B W}<T \\ 1, & I_{B W} \geq T\end{cases}
$$


dengan

$I_{\text {bin }}(x, y) \quad=$ Intensitas warna biner pada koordinat $x$ dan $y$.

T $\quad$ Threshold .

\subsection{Segmentasi}

Suatu citra menjadi beberapa daerah atau objek yang dimilikinya dengan cara melakukan segmentasi terhadap objek yang ada dalam citra tersebut. Menurut Castleman (1996), segmentasi citra merupakan suatu proses memecah suatu citra menjadi banyak segmen atau bagian daerah yang tidak saling bertabrakan (non-overlapping).Dalam citra digital daerah hasil segmentasi tersebut merupakan kelompok pixel yang bertetangga atau berhubungan. Proses segmentasi digunakan dalam berbagai penerapan, meskipun metode yang digunakan bervariasi, namun memiliki tujuan yang sama yaitu mendapatkan representasi sederhana yang berguna dari suatu citra. Segmentasi dapat dilakukan melalui beberapa pendekatan, menurut Castleman terdapat 3 macam pendekatan, yaitu :

1. Pendekatan batas (boundary approach)

2. Pedekatan tepi (edge approach)

3. Pendekatan daerah (region approach)

\subsection{Nilai Batas Ambang}

Thresholding adalah istilah yang digunakan dalam Pengolahan Citra Digital untuk sebah nilai batas ambang, yang merupakan salah satu teknik segmentasi yang baik digunakan untuk citra dengan perbedaan nilai intensitas yang signifikan antara latar belakang dan objek utama (Katz, 2000). Dalam pelaksanaannya Thresholding membutuhkan suatu nilai yang digunakan sebagai nilai pembatas antara objek utama dengan latar belakang, dan nilai tersebut dinamakan dengan threshold.

Thresholding digunakan untuk mempartisi citra dengan mengatur nilai intensitas semua piksel yang lebih besar dari nilai threshold $T$ sebagai latar depan dan yang lebih kecil dari nilai threshold $T$ sebagai latar belakang. Biasanya pengaturan nilai threshold dilakukan berdasarkan histogram grayscale (Gonzales dan Woods, 2002; Fisher, dkk, 2003; Xiaoyi dan Mojon, 2003). Pencarian metode threshold yang sedehana tidak memerlukan pengetahuan yang lebih tentang citra dan thresholding pun bisa bekerja pada citra yang memiliki noise, Metode iterative merupakan pendekatan yang baik untuk mencari nilai batas ambang.

\subsection{Metode Ringelmann}

Metode ini merupakan salah satu cara yang banyak digunakan dalam menentukan opasitas asap hitam. Dalam metode ini terdapat yang namanya skala Ringlemann berskala 0-5 yang berguna untuk penentuan opasitas asap hitam. Metode Ringlemann merupakan metode yang secara sah digunakan dalam penentuan opasitas asap hitam di Indonesia. Metode ini telah ter Standar Nasional Indonesia dengan nomor SNI 19-7117.11-2005. SNI 19-7117.11-2005 ini dikembangkan sesuai Method 9 USEPA. Jadi dalam penentuan opasitas asap hitam di Indonesia harus menggunakan SNI ini. Cara uji prinsip ini ialah dengan membandingkan warna asap yang keluar dari cerobong dengan warna skala Ringlemann.

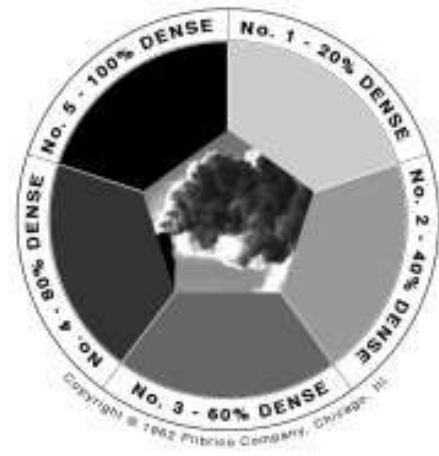

Gambar 2 : Skala Ringgelman

Syarat-syarat yang harus dipenuhi saat pemantauan opasitas (BSN, 2005) ialah 
a. Posisi matahari dibelakang pengamat (dalam daerah $140^{\circ}$ ).

b.Latar belakang sebaiknya langit biru bila kondisi ini tidak tercapai diberi keterangan pada formulir lapangan.

c. Arah angin pada sudut $90^{\circ}$ terhadap pengamat.

d. Jarak pengamat tiga kali ketinggian cerobong.

e. Tidak ada halangan yang mempengaruhi pengamatan.

Tabel 1 : Representasi Skala Ringgelmann

\begin{tabular}{|c|c|c|}
\hline $\begin{array}{c}\text { Skala } \\
\text { Ringlemann }\end{array}$ & $\begin{array}{c}\text { Transmisi cahaya } \\
\text { melalui asap (\%) }\end{array}$ & $\begin{array}{c}\text { Opasitas } \\
(\%)\end{array}$ \\
\hline $\mathbf{0}$ & $\mathbf{1 0 0}$ & $\mathbf{0}$ \\
\hline 1 & $\mathbf{8 0}$ & $\mathbf{2 0}$ \\
\hline 2 & 60 & 40 \\
\hline 3 & 40 & 60 \\
\hline 4 & 20 & $\mathbf{8 0}$ \\
\hline 5 & 0 & 100 \\
\hline
\end{tabular}

\subsection{Image Compositing}

Image compositing merupakan teknik yang digunakan untuk melakukan rendering beberapa gambar dengan tujuan agar gambar yang dihasilkan dapat terlihat lebih jelas dan lebih menghemat waktu. Dalam teknik kompositing ini dikenal namanya Premultiplied Alpha $(\alpha)$ yang merupakan tingkat kecerahan dari suatu gambar. Semakin besar suatu $\alpha$ dari suatu gambar maka gambar tersebut akan semakin terlihat dibanding gambar yang lain, begitu pula sebaliknya semakin kecil nilai $\alpha$ maka gambar tersebut akan semakin tidak terlihat.

$$
A B=\alpha * A+(1-\alpha) * B
$$

dengan

$A B=$ Hasil rendering gambar $A$ dan $B$.

$A=$ Citra gambar $A$.

$B=$ Citra gambar $B$.

$\alpha=$ Tingkat kecerahan gambar.

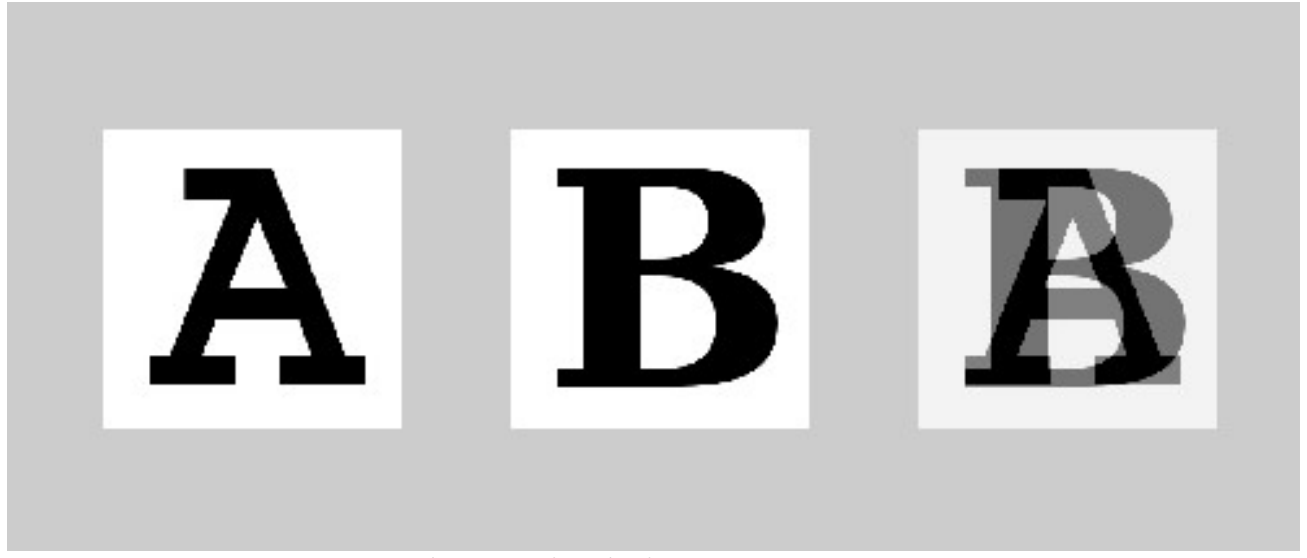

Gambar 3 : Simulasi Image Compositing

\subsection{Polarisasi Allright}

Pada proses ini cahaya yang berasal dari matahari tersebar ke arah pengamat. Penyebaran cahaya tersebut disebabkan oleh partikel di atmosfir. Semakin jauh jarak objek yang diambil maka semakin besar pula airlight yang terjadi. 




Pada Gambar 4 airlight meningkat dengan jarak $z$ dari objek

$$
A=A_{\infty}\left(1-e^{-\beta z}\right)
$$

dengan

$\beta=$ Koefisien yang tersebar

$A=$ airlight

$z=$ jarak objek dengan kamera

$A_{\infty}=$ airlight yang berhubungan dengan object pada jarak takhingga, seperti langit.

\section{Hasil dan Pembahasan}

Peneltian yang dilakukan ialah pengembangan teknologi imaging dalam penentuan parameter opasitas asap hitam pada cerobong industri. Metode pengukuran yang digunakan dalam pemantauan ini adalah Metode Ringlemann. Adapun data yang akan diolah ialah berupa citra suatu gambar diam. Pengambilan data citra ini dilakukan sesuai dengan ketentuan SNI 19-7117.11-2005.

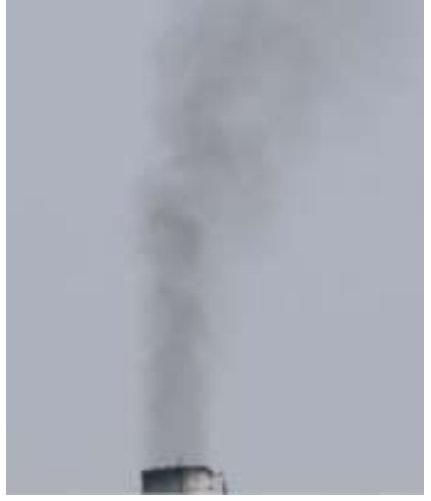

Gambar 1 : Objek Penelitian

Langkah pertama yang akan dilakukan ialah memotong gambar diatas menjadi 3 bagian yaitu daerah asap yang dekat dengan cerobong, daerah asap yang berada ditengah dan daerah asap yang jauh dari cerobong (menetapkan ROI dengan cara membuang bagian gambar yang tidak dinginkan). Langkah selanjutnya ialah dilakukan segmentasi Gambar (5) menjadi 2 objek yaitu objek langit dan objek asap. 


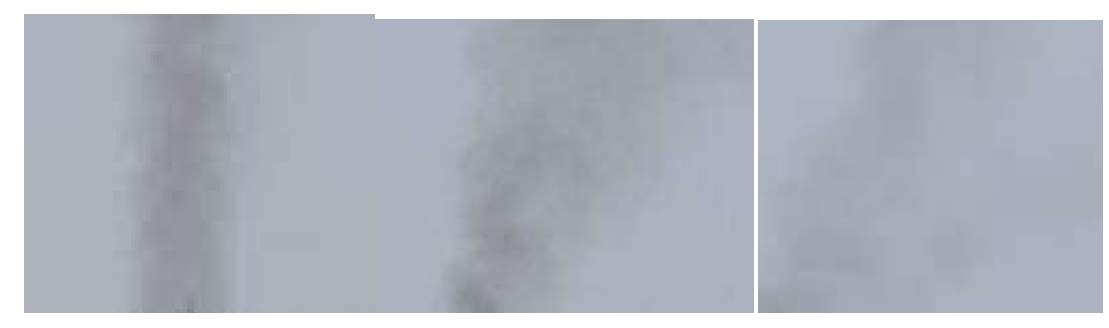

a

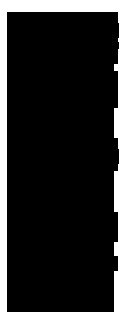

d



g $\mathrm{b}$
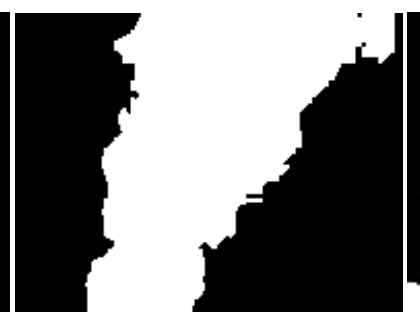

e

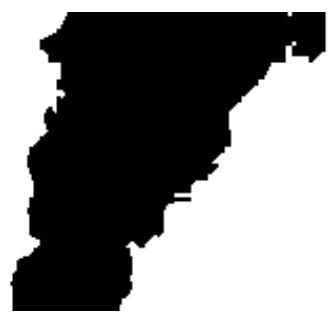

$\mathrm{h}$ c


i

Gambar 2 : (a) ROI Dekat Cerobong, (b) ROI Asap di Tengah Langit, (c) ROI Ujung Asap, (d),(e),(f) Segmentasi Asap, (g),(h),(i) Segemntasi Langit

Selanjutnya akan dicari nilai rata-rata Lab pada setiap hasil segmentasi asap dan langit. Nilai rata-rata Lab akan digunakan pada teknik kompositing dan polarisasi airlight untuk mendapatkan fungsi persamaan opasitas. Adapun fungsi persamaan opasitas didapatkan menggunakan pendekatan logaritmik.

$$
f(\beta)=\exp \left(\frac{\beta-2,3433}{-0,95}\right)
$$

Fungsi diatas berguna untuk mendapatkan tingkat kecerahan atau opasitas asap hitam pada cerobong asap industri.

\section{Kesimpulan}

Setelah melakukan berbagai percobaan sehingga memperoleh beberapa data untuk dilakukan analisis pada bab-bab sebelumnya, maka keseimpulan dari penelitian ini ialah algoritma segmentasi yang digunakan pada penelitian ini ialah menggunakan thresholding. Hasil dari algoritma pada penelitian ini ialah didapatkannya fungsi untuk bisa menentukan tingkat parameter opasitas asap hitam. Pencarian fungsi dilakukan dengan pendekatan logaritmik. Fungsi dengan nilai $R^{2}$ terbesar yang dipilih.

Melakukan pendeteksian opasitas asap hitam yang akurat secara tidak langsung sama dengan mencegah pencemaran udara, sehingga resiko pencemaran udara sedikit berkurang. Untuk itu pada penelitian selanjutnya kami menyarankan beberapa hal untuk perkembangan sistem ini.Algoritma dalam melakukan segmentasi bisa dikembangkan menggunakan bentuk tekstur maupun warna agar hasil segmentasi yang didapat bisa lebih akurat baik saat langit cerah maupun mendung. 


\section{Ucapan Terima Kasih}

Dalam penyusunan dan penulisan laporan ini tidak terlepas dari bantuan, bimbingan serta dukungan dari berbagai pihak. Oleh karena itu dalam kesempatan ini penulis dengan senang hati menyampaikan terima kasih kepada yang terhormat: Ibu Primadina Hasanah, S.Si., M.Sc., sebagai dosen pembimbing yang telah memberikan bimbingan dan dorongan dalam penyusunan, Bapak Dr. Esa Prakasa, M.T., selaku pembimbing lapangan yang telah memberikan banyak bimbingan, masukan dan dorongan dalam penyusunan laporan kerja praktik, dan Ayah dan Ibu yang telah membesarkan dan mendidik, serta memberikan dukungan dan doa kepada penulis, serta rekan-rekan di Prodi Matematika, Institut Teknologi Kalimantan yang juga telah banyak memberikan dukungan dan motivasi kepada penulis.

\section{References}

Badan Pusat Statistik (BPS) Indonesia. 23 Agustus 2016. (2010).

Badan Standarisasi Nasional (BSN). (2005). Standar Nasional Indonesia (SNI) Emisi Gas Buang - Sumber Tidak Bergerak - Bagian 11 : Cara uji opasitas menggunakan skala Ringelmann untuk asap hitam. SNI 18-7117.112005. BSN. Indonesia.

Kil, T. H. dkk. (2013). A Dehazing Algorithm Using Dark Channel Prior And Contrast. IEEE, 2484-2487.

Porter, T., Duff, T. (1984). Compositing Digital Image. Computer Graphics Volume 18, Number 3, $253-259$.

Schechner, Y. Y. dkk. (2001). Instant Dehazing of Images Using Polarization. IEEE, I-325 - I-332.

Smith, Alvy Ray.(1995). Image Compositing Fundamental. Microsoft Tech Memo 4.

www.soliftec.com. 2010. The Ringelmann Smoke Chart. Soliftec. 23 Agutus 2016

Yudhistira, D.D. dan Ayusari, M.D. (2016). Pengukuran Tingkat Opasitas Udara Emisi Pada Pembakaran Karet, Kain, dan Kertas Menggunakan Opacity Meter. Institut Pertanian Bogor. 